\title{
Influences on the Seismic Response of the Gravity Dam-Foundation-Reservoir System with Different Boundary and Input Models
}

\author{
Denghong Chen $\mathbb{D}^{1,2}$ Chunping Hou $\mathbb{D}^{1},{ }^{2}$ and Feng Wang $\mathbb{D}^{3}$ \\ ${ }^{1}$ State Key Laboratory of Simulation and Regulation of Water Cycle in River Basin, \\ China Institute of Water Resources and Hydropower Research, Beijing 100048, China \\ ${ }^{2}$ College of Civil Engineering \& Architecture, China Three Gorges University, Yichang, Hubei 443002, China \\ ${ }^{3}$ College of Hydraulic \& Environmental Engineering, China Three Gorges University, Yichang, Hubei 443002, China
}

Correspondence should be addressed to Denghong Chen; d.chen@ctgu.edu.cn and Feng Wang; wangfengctgu@ctgu.edu.cn

Received 3 November 2020; Revised 28 January 2021; Accepted 19 February 2021; Published 3 March 2021

Academic Editor: Zhixiong Li

Copyright (c) 2021 Denghong Chen et al. This is an open access article distributed under the Creative Commons Attribution License, which permits unrestricted use, distribution, and reproduction in any medium, provided the original work is properly cited.

\begin{abstract}
Dynamic dam-foundation interaction is great important in the design and safety assessment of the dam structures. Two classic boundary conditions, i.e., the viscous-spring boundary and the viscous boundary, are employed to consider the radiation damping of the unbounded rock foundation. The input models of seismic excitation of the viscous-spring boundary and the viscous boundary are derived. The accuracy of the two boundary conditions in the dynamic analysis of the dam foundation is verified through the foundation analysis using an impulsive load. The influences of two boundary conditions and their earthquake input models on the seismic analysis of the Pine Flat and Jin'anqiao gravity dam-foundation-reservoir systems are then investigated. The results of displacements, hydrodynamic pressure, and principal stresses show that the agreement between the results of the viscous-spring boundary and viscous boundary is good. The relative errors of the two models in the Pine Flat and Jin'anqiao gravity dams are both less than $5 \%$. They are both acceptable from an engineering point of view.
\end{abstract}

\section{Introduction}

Dynamic dam-foundation interaction is of importance in the design and safety assessment of the dam structures. The main challenge in this topic is the accurate modelling of the unbounded domain, i.e., the radiation damping at infinity. A rational and commonly used approach for modelling the whole system is to divide it into two parts. The first part is the near-field bounded domain, which contains the dam structure and a part of the adjacent foundation rock and can be efficiently modelled by the finite element method (FEM). The second part is the far-field unbounded domain, which includes the rest of the infinite foundation. The wellestablished finite element method cannot be used straightforwardly, since the outgoing waves are reflected at the artificial boundaries of the finite element mesh. In 1970s, Clough et al. [1] proposed a massless foundation model to avoid the use of large foundation models, in which only the effects of foundation flexibility are considered. This model is adopted by the well-known EACD-3D [2] and ADAP-88 [3] programmes and considered as a standard method by U.S. Army Corps of Engineers [4]. However, there are some shortcomings with the massless foundation model. For example, the effect of radiation damping on energy dispersion for a far-field foundation cannot be considered. Stresses may be overestimated by a factor of 2-3 [5] if the foundation-rock mass and damping is ignored.

Many numerical methods have been employed to study the dynamic dam-foundation interaction including rigid, massless, and massed foundation models. Many scholars have studied the infinite domain and the difficulty in overcoming 
the interaction and the practical calculation method from different levels [6, 7]. In particular, a forward-looking breakthrough has been made in the artificial boundary simulation of infinite domain. These include the viscous boundary [8], viscous-spring boundary [9-12], multitransmitting boundary $[13,14]$, the scaled boundary finite element method [15-19], infinite elements [20-23], the perfectly matched layers (PMLs) [24-26], and high-order absorbing boundary conditions.

The viscous boundary was proposed by Lysmer and Kuhlemeyer [8]. Its basic idea is to set dashpots on the artificial truncation boundary. The dashpots are placed to absorb the energy radiated outward during vibration. The concept of the viscous boundary is very clear, and it can be easily implemented in finite element programs. It has been embedded in many types of large commercial software, such as LS-DYNA, FLAC, ABAQUS, and etc. As a classic local procedure, the viscous boundary has been widely used since it was proposed. Burman et al. [27] established a simplified method of dynamic soil-structure interaction by using the viscous boundary and analyzed the seismic response of Koyna dam. Hariri-Ardebili and Mirzabozorg [28] performed a comparative study of seismic stability of the coupled arch dam-foundation-reservoir systems using infinite elements and viscous boundary models. It was found that the responses of the system with the massed foundation including either infinite elements or viscous boundary on the far-end face of the foundation are the same. Hariri-Ardebili and Kianoush [29] investigated the seismic response of a coupled damreservoir-foundation system under different types of artificially generated ground motions, in which the foundation rock was modelled as massed medium and the viscous boundary model was applied on the exterior surface of the foundation. Mandal and Maity [30] proposed a two-dimensional direct coupling methodology to obtain the response of the dam-reservoir-foundation system considering fluid-structure and soil-structure interaction simultaneously. Løkke and Chopra [31-33] employed the standard viscousdamper absorbing boundaries to model the semi-unbounded foundation and fluid domains and presented a direct finite element (FE) method for nonlinear response history analysis of $2 \mathrm{D}$ and $3 \mathrm{D}$ semi-unbounded dam-water-foundation systems. Mohammadnezhad et al. [34] and Sotoudeh et al. [35] developed a finite element model for earthquake analysis of a concrete gravity dam-foundation-reservoir system, where the viscous boundary condition is applied at the truncated foundation boundary to simulate the radiation damping of the semi-unbounded foundation rock. Karalar and Çavuşli [36-38] adopted the viscous boundary and viscoplastic material model to analyze the seismic response of the CFR dams under different reservoir water levels.

As another classic local procedure, the viscous-spring boundary consists of the parallel-connected spring-dashpot system in the normal and tangential directions. It is very simple, frequency independent, and efficient. It can also be conveniently incorporated into commercial finite element software. In addition, it provides sufficient accuracy without a significant increase in the computational effort. Zhang et al. [39] and Pan et al. [40] studied the radiation damping on the seismic response of arch dams by using the massless foundation model and viscous-spring boundary input model. Chen et al. [41] developed a new viscous-spring boundary element capable of reflecting the radiation damping effects of an infinite foundation and the external source wave input subroutine in ABAQUS. Wang et al. [42] integrated a comprehensive model to analyze the nonlinear earthquake response of arch dams. Mandal and Maity [43] adopted a cone-type local nonreflecting boundary condition (spring-dashpot artificial boundary) to model the semiinfinite soil domain and conducted the seismic analysis of the dam-foundation coupled system considering a direct coupling approach. Chen et al. [44] established a comprehensive and integral analysis model of the dam-foundation-reservoir water interaction system based on the viscous-spring boundary and its corresponding free field input mechanism. Guo et al. [45] established a dynamic analysis model of a dam-foundationreservoir system in consideration of the interactions between the gravity dam and foundation and the radiation damping effect of the far-field boundary based on the contact model together with the viscous-spring boundary conditions.

However, as two typical procedures, few of the above studies show their differences of the seismic responses of the concrete dam-foundation-reservoir system. This study seeks to better understand what are the detailed differences of the seismic responses of the gravity dam system with viscous, viscous-spring boundary conditions, and the seismic input models. This study is organised as follows. Section 2 presents the modelling of the dynamic dam-foundation interaction system by using the viscous boundary and the viscous-spring boundary, respectively. Section 3 presents the seismic response analysis of the gravity dam-foundation-reservoir system. First, the accuracy of the two boundary conditions in the dynamic analysis of the dam foundation is verified through the foundation analysis using an impulsive load. Then, the influences of two boundary conditions and their earthquake input models on the seismic analysis of the Pine Flat and Jin'anqiao gravity dam systems are investigated. Section 4 summarises some major conclusions from this study.

\section{Modelling the Dynamic Dam-Foundation Interaction System}

The dynamic finite element formulation for the damfoundation system is expressed as follows:

$$
\begin{aligned}
& {\left[\begin{array}{ll}
{\left[M_{S S}\right]} & {\left[M_{S B}\right]} \\
{\left[M_{B S}\right]} & {\left[M_{B B}\right]}
\end{array}\right]\left\{\begin{array}{l}
\left\{\ddot{u}_{S}\right\} \\
\left\{\ddot{u}_{B}\right\}
\end{array}\right\}+\left[\begin{array}{ll}
{\left[C_{S S}\right]} & {\left[C_{S B}\right]} \\
{\left[C_{B S}\right]} & {\left[C_{B B}\right]}
\end{array}\right]\left\{\begin{array}{l}
\left\{\dot{u}_{S}\right\} \\
\left\{\dot{u}_{B}\right\}
\end{array}\right\}} \\
& +\left[\begin{array}{cc}
{\left[K_{S S}\right]} & {\left[K_{S B}\right]} \\
{\left[K_{B S}\right]} & {\left[K_{B B}\right]}
\end{array}\right]\left\{\begin{array}{c}
\left\{u_{S}\right\} \\
\left\{u_{B}\right\}
\end{array}\right\}=\left\{\begin{array}{c}
\{0\} \\
\left\{F_{B}\right\}
\end{array}\right\},
\end{aligned}
$$

where $[M],[C]$, and $[K]$ are the mass matrix, damping matrix, and stiffness matrix of the system, respectively; $\{\ddot{u}\}$, $\{\dot{u}\}$, and $\{u\}$ are the acceleration, velocity, and displacement 
vectors, respectively. $\{F\}$ is an interaction force vector acting at the dam-foundation interface. The subscript $S$ describes the nodes belonging only to the bounded domain (dam and part of foundation). $B$ denotes the nodes at the boundary belonging to both, the bounded and unbounded domains.

The unbounded domain is truncated, but its earthquake input and radiation damping effects should be considered. The response of the unbounded domain can be decomposed into the scattered and free fields. It can be written at the truncated boundary as

$$
\begin{aligned}
& \left\{F_{B}\right\}=\left\{F_{B}^{s}\right\}+\left\{F_{B}^{f}\right\}, \\
& \left\{u_{B}\right\}=\left\{u_{B}^{s}\right\}+\left\{u_{B}^{f}\right\}, \\
& \left\{\dot{u}_{B}\right\}=\left\{\dot{u}_{B}^{s}\right\}+\left\{\dot{u}_{B}^{f}\right\},
\end{aligned}
$$

where the superscripts $s$ and $f$ denote the scattered and free fields, respectively. The scattered field is represented by a suitable boundary condition imposed on the truncated boundary.

\subsection{Modelling the Dam-Foundation System by the Viscous Boundary}

2.1.1. Viscous Boundary. Lysmer and Kuhlemeyer [8] proposed the first transmitting boundary for elastodynamics. It is often referred to as classical viscous boundary. For 2D cases, the viscous boundary condition is formulated as

$$
\left\{F_{B}^{s}\right\}=-\left[C_{B}\right]\left\{\dot{u}_{B}^{s}\right\}
$$

where $\left[C_{B}\right]$ is the damping matrix of the unbound domain. For the bottom boundary, $\left[C_{B}\right]$ is denoted as $\left[\begin{array}{cc}\rho c_{s} A & 0 \\ 0 & \rho c_{p} A\end{array}\right]$; for the lateral boundaries, $\left[C_{B}\right]$ is denoted as $\left[\begin{array}{cc}\rho c_{p} A & 0 \\ 0 & \rho c_{s} A\end{array}\right]$, in which $c_{s}$ and $c_{p}$ are the wave velocities of the $S$-wave and $\mathrm{P}$-wave, respectively; $\rho$ is the mass density of the medium; $A$ is the total area of all elements around a node at the boundary.

2.1.2. Seismic Input Using the Viscous Boundary. Substituting equations (2)-(4) into equation (1) leads to

$$
\begin{gathered}
{\left[\begin{array}{cc}
{\left[M_{S S}\right]} & {\left[M_{S B}\right]} \\
{\left[M_{B S}\right]} & {\left[M_{B B}\right]}
\end{array}\right]\left\{\begin{array}{l}
\left\{\ddot{u}_{S}\right\} \\
\left\{\ddot{u}_{B}\right\}
\end{array}\right\}+\left[\begin{array}{cc}
{\left[C_{S S}\right]} & {\left[C_{S B}\right]} \\
{\left[C_{B S}\right]} & {\left[C_{B B}\right]+\left[C_{B}\right]}
\end{array}\right]} \\
\cdot\left\{\begin{array}{l}
\left\{\dot{u}_{S}\right\} \\
\left\{\dot{u}_{B}\right\}
\end{array}\right\}+\left[\begin{array}{ll}
{\left[K_{S S}\right]} & {\left[K_{S B}\right]} \\
{\left[K_{B S}\right]} & {\left[K_{B B}\right]}
\end{array}\right]\left\{\begin{array}{l}
\left\{u_{S}\right\} \\
\left\{u_{B}\right\}
\end{array}\right\}=\left\{\begin{array}{c}
\{0\} \\
\left\{F_{B}^{\infty}\right\}
\end{array}\right\},
\end{gathered}
$$

with the effective earthquake forces

$$
\left\{F_{B}^{\infty}\right\}=\left[C_{B}\right]\left\{\dot{u}_{B}^{f}\right\}+\left\{F_{B}^{f}\right\}
$$

where $\left\{u_{B}^{f}\right\}$ and $\left\{\dot{u}_{B}^{f}\right\}$ are the free field displacement and velocity vectors, respectively. $\left\{F_{B}^{f}\right\}$ is the free field force which is calculated by the elastic theory. The effective earthquake forces are applied both on the bottom and on the side boundaries of the foundation.

\subsection{Modelling the Dam-Foundation System by the Viscous- Spring Boundary}

2.2.1. Viscous-Spring Boundary. The viscous boundary is a special case of the viscous-spring boundary with zero stiffness. A 2D sketch of the viscous-spring boundary used in the gravity dam-foundation system and the parallel-connected spring-dashpot system in each direction is shown in Figure 1. The formulation of the viscous-spring boundary is written as

$$
\left\{F_{B}^{s}\right\}=-\left[K_{B}\right]\left\{u_{B}^{s}\right\}-\left[C_{B}\right]\left\{\dot{u}_{B}^{s}\right\},
$$

where $\left[K_{B}\right]$ and $\left[C_{B}\right]$ are the stiffness and damping matrices of the unbound domain, respectively. For the bottom boundary, $\left[K_{B}\right]$ is denoted as $\left[\begin{array}{cc}K_{B T} & 0 \\ 0 & K_{B N}\end{array}\right]$; for the lateral boundaries, $\left[K_{B}\right]$ is denoted as $\left[\begin{array}{cc}K_{B N} & 0 \\ 0 & K_{B T}\end{array}\right] .\left[C_{B}\right]$ has a similar form and is denoted from $\left[K_{B}\right]$ by replacing $K$ with C.

The normal and tangential spring and damping coefficients [10] of the viscous-spring boundary are defined as follows:

$$
\left\{\begin{array}{l}
K_{B N}=\alpha_{N} \frac{G}{r_{b}} A, C_{B N}=\rho c_{p} A, \\
K_{B T}=\alpha_{T} \frac{G}{r_{b}} A, C_{B T}=\rho c_{s} A,
\end{array}\right.
$$

where $K_{B N}$ and $K_{B T}$ are the normal and tangential stiffness coefficients, respectively. $C_{B N}$ and $C_{B T}$ are the normal and tangential damping coefficients, respectively. $r_{b}$ is the distance from the scattering wave source to the artificial boundary point. $G$ is the shear modulus of the medium, in which $G=\rho c_{s}^{2}$ and $\lambda+2 G=\rho c_{p}^{2} \cdot \alpha_{N}$ and $\alpha_{T}$ are the dimensionless parameters, which are given values of 1.0 and 0.5 [10], respectively. $A$ is the total area of all elements around a node at the boundary.

The viscous-spring boundary can be implemented easily by the commercial finite element software, such as the springs/dashpots in ABAQUS/Standard [46].

2.2.2. Seismic Input Using the Viscous-Spring Boundary. Substituting equation (2), (3a) and (3b), and (7) into equation (1) leads to

$$
\begin{gathered}
{\left[\begin{array}{c}
{\left[M_{S S}\right]\left[M_{S B}\right]} \\
{\left[M_{B S}\right]\left[M_{B B}\right]}
\end{array}\right]\left\{\begin{array}{l}
\left\{\ddot{u}_{S}\right\} \\
\left\{\ddot{u}_{B}\right\}
\end{array}\right\}+\left[\begin{array}{cc}
{\left[C_{S S}\right]} & {\left[C_{S B}\right]} \\
{\left[C_{B S}\right]} & {\left[C_{B B}\right]+\left[C_{B}\right]}
\end{array}\right]\left\{\begin{array}{l}
\left\{\dot{u}_{S}\right\} \\
\left\{\dot{u}_{B}\right\}
\end{array}\right\}} \\
+\left[\begin{array}{c}
{\left[K_{S S}\right]} \\
{\left[K_{B S}\right]\left[K_{S B}\right]+\left[K_{B}\right]}
\end{array}\right]\left\{\begin{array}{l}
\left\{u_{S}\right\} \\
\left\{u_{B}\right\}
\end{array}\right\}=\left\{\begin{array}{c}
\{0\} \\
\left\{F_{B}^{\infty}\right\}
\end{array}\right\},
\end{gathered}
$$

with the effective earthquake forces 


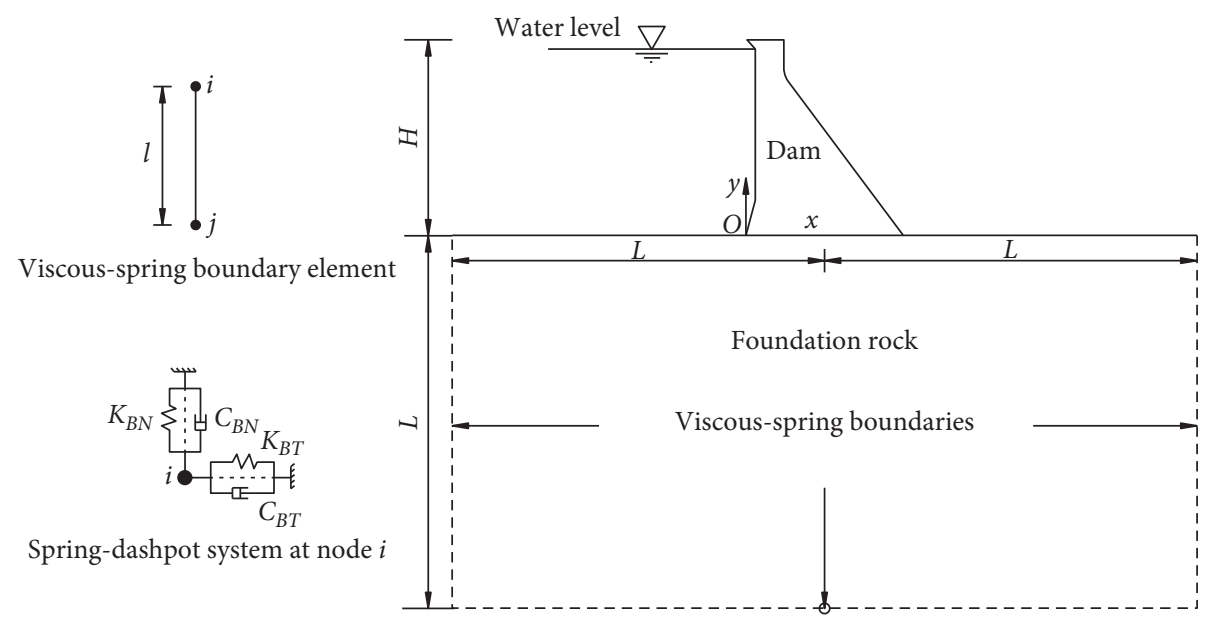

FIgURE 1: Viscous-spring boundary of the dam-foundation system.

$$
\left\{F_{B}^{\infty}\right\}=\left[K_{B}\right]\left\{u_{B}^{f}\right\}+\left[C_{B}\right]\left\{\dot{u}_{B}^{f}\right\}+\left\{F_{B}^{f}\right\} .
$$

The ABAQUS/Standard-based wave input subroutine, SDAB for $[41,44]$, for the viscous-spring boundary is created using FORTRAN. The wave field at the truncated boundary is separated into a free field without local topography effects and a scattering field induced by local topography effects. The free field of the seismic action at the truncated boundary is expressed generally using the seismic time histories for displacement and velocity. The free field is carried out by the loading subroutines of DSLOAD and UTRACLOAD, which describes the normal and tangential loads, respectively.

\section{Seismic Response Analysis of the Gravity Dam Systems}

3.1. Foundation Analysis Using an Impulsive Load. To investigate the effect of foundation size and to verify the accuracy of the nonreflecting boundary conditions in the dynamic analysis of the dam foundation, a simple foundation block with $L=700 \mathrm{~m}, H=122 \mathrm{~m}, L_{1}=20 \mathrm{~m}$, and $L_{2}=100 \mathrm{~m}$ [47], as shown in Figure 2, is considered. The side boundaries and the base boundary are represented by different absorbing boundary conditions. To evaluate how well the absorbing boundary conditions perform, this example explores the dynamic response to a vertically propagating SV wave by using an impulsive signal. The velocity and the Fourier amplitude spectrum of the impulsive load are shown in Figure 3. This velocity pulse has a maximum amplitude of $0.01 \mathrm{~m} / \mathrm{s}$.

The properties of the rock foundation are as follows: modulus of elasticity $E_{\mathrm{r}}=22.41 \mathrm{GPa}$, Poisson's ratio $\nu_{r}=0.20$, mass density $\rho_{\mathrm{r}}=2483 \mathrm{~kg} / \mathrm{m}^{3}$, the shear wave velocity $c_{s}=1939 \mathrm{~m} / \mathrm{s}$, and the compressional wave velocity $c_{p}=3167 \mathrm{~m} / \mathrm{s}$. In the $\mathrm{FE}$ analysis, plane strain state is considered. The frequency content of the impulsive load is determined by the depth $H$ (Figure 2), minimum element size, and material properties of the foundation. To avoid inaccuracies, the highest frequency $f_{1}$ of the impulse is selected so that the wavelength is greater than 10 times the

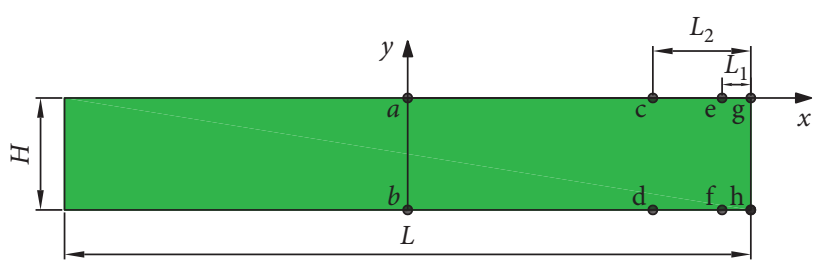

FIgURE 2: Configuration of the foundation block.

spatial element size $h$, leading to the condition $\left(c_{s} / f_{1}\right) \geq 10 h$. The highest frequency $f_{1}$ is selected as $130 \mathrm{~Hz}$ in this example [48], and the maximum element size $h$ is determined as $1.5 \mathrm{~m}$. The foundation block is discretized with 37827 fournode elements, leading to 38376 nodes. The viscous-spring and viscous boundary conditions and their seismic input models are considered. In the viscous-spring boundary model, the parameter $r_{b}$ in equation (8) is taken as $350 \mathrm{~m}$ in this example. The effective earthquake forces are calculated by equation (10).

Time histories of the horizontal velocities of the free surface points $a, c$, e and bottom points $b, d, f$ are plotted in Figure 4. From the results, it could clearly be seen that the maximum velocities of the free surface points $0.02 \mathrm{~m} / \mathrm{s}$ are nearly twice the corresponding peak amplitude of the input wave $0.01 \mathrm{~m} / \mathrm{s}$. Additionally, the velocities of the bottom points are basically the same, with the first half of the velocity time history showing the input wave and the latter part of the velocity time history showing the reflection wave. The results of viscous-spring boundary and viscous boundary both agree well with the theoretical solutions. And the change law of the results is consistent with that in the literature [47].

\subsection{Seismic Analysis of the Pine Flat Dam-Foundation-Reservoir} System. The tallest nonoverflow dam monolith (no. 16, as shown in Figure 5) of the Pine Flat gravity dam [47] is selected as the first engineering example. The seismic response analysis of the dam-foundation-reservoir system is performed considering the elastic material properties. 


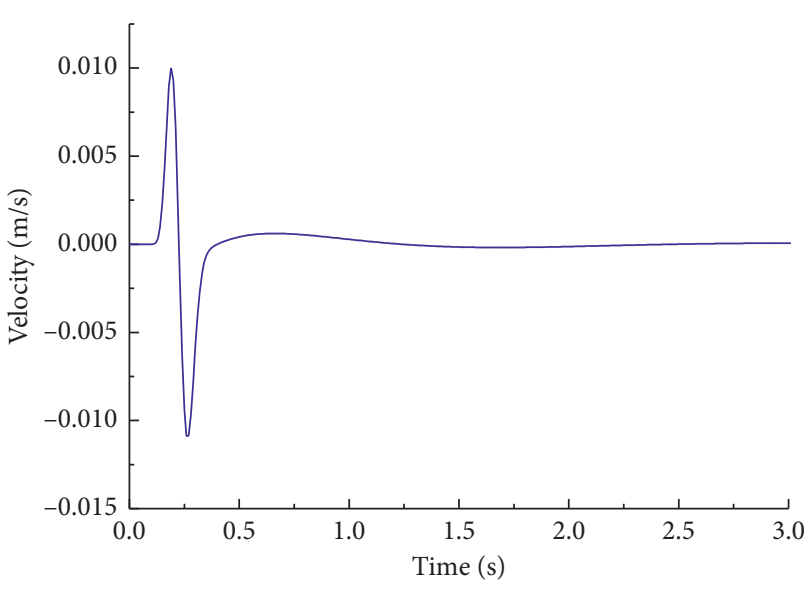

(a)

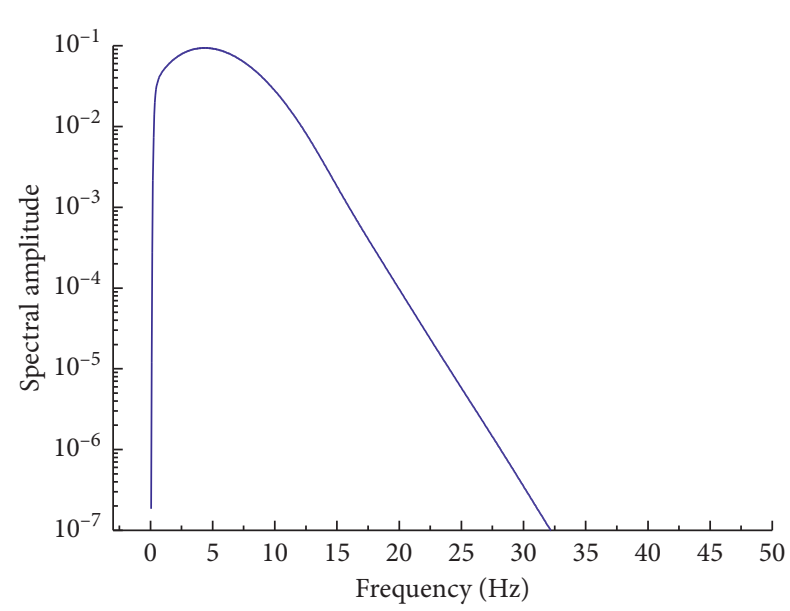

(b)

FIgUre 3: Time history of the impulsive load. (a) Time domain. (b) Fourier amplitude spectrum.

The concrete properties are modulus of elasticity $E_{c}=22.41 \mathrm{GPa}$, Poisson's ratio $\nu_{c}=0.20$, and mass density $\rho_{c}=2483 \mathrm{~kg} / \mathrm{m}^{3}$. The rock foundation is assumed to be homogeneous, isotropic, and elastic with the same properties in Section 3.1. The hydrodynamic pressure wave velocity is $c=1439 \mathrm{~m} / \mathrm{s}$, and the density of reservoir water is $\rho_{w}=1000 \mathrm{~kg} / \mathrm{m}^{3}$. In the investigations, Rayleigh viscous damping (Rayleigh damping) proportional to a linear combination of mass matrix $(M)$ and stiffness matrix $(K)$ and constants of proportionality $\alpha$ and $\beta$, respectively, i.e.,

$$
[C]=\alpha[M]+\beta[K],
$$

is considered. The constants of proportionality are assumed as $0.751 / \mathrm{s}$ for $\alpha$ and $0.0005 \mathrm{~s}$ for $\beta$, which corresponds to an approximately $2 \%$ damping ratio for the dam and foundation rock.

A 2D finite element method (FEM) mesh of the Pine Flat dam-reservoir-foundation system is shown in Figure 6. The foundation block in Section 3.1 is adopted in this analysis. The system is discretized with 6417 fournode plane strain elements, leading to 6720 nodes, in which there are 756, 4212, and 1449 elements for the dam, foundation, and reservoir water, respectively. Solid elements for dam and foundation (with Rayleigh damping) are adopted, and acoustic fluid elements [48] for water in reservoir are used. The tie constraints are applied at the dam-water and water-rock interfaces to couple accelerations with hydrodynamic pressures. In addition, the upstream truncated boundary of the reservoir is provided with the nonreflecting acoustic condition [49]. The deconvolved and baseline-corrected S69E component of the Taft record (Figure 7) with a peak horizontal acceleration of $0.132 \mathrm{~g}$ is used and considered as a vertically propagated SV wave for the seismic input. The total calculation time is $54.16 \mathrm{~s}$. The fixed time step $\Delta t=0.01 \mathrm{~s}$ is selected in the calculation.

Result comparisons of the Pine Flat dam using different models are listed in Table 1. Time histories of horizontal displacements at dam crest and dam heel are plotted in
Figure 8. Time histories of relative horizontal displacements of dam crest and dam heel are shown in Figure 9. For the solutions by using the viscous-spring boundary and viscous boundary, the maximum horizontal displacements at dam crest are $17.43 \mathrm{~cm}$ and $17.36 \mathrm{~cm}$, in which the relative error is $0.39 \%$. The maximum horizontal displacements at dam heel are $17.387 \mathrm{~cm}$ and $17.311 \mathrm{~cm}$, in which the relative error is $0.44 \%$. The maximum relative horizontal displacements of dam crest and dam heel are $-5.13 \mathrm{~cm}$ and $-5.06 \mathrm{~cm}$, in which the relative error is $1.47 \%$.

Time histories of horizontal accelerations at dam crest are plotted in Figure 10. For the solutions by using the viscous-spring boundary and viscous boundary, the maximum horizontal accelerations at dam crest are $12.39 \mathrm{~m} / \mathrm{s}^{2}$ and $12.15 \mathrm{~m} / \mathrm{s}^{2}$, in which the relative error is $1.87 \%$. Time histories of the hydrodynamic pressure at dam heel are shown in Figure 11. For the solutions by using the viscousspring boundary and viscous boundary, the maximum hydrodynamic pressures at dam heel are $-0.2155 \mathrm{MPa}$ and $-0.2159 \mathrm{MPa}$, in which the relative error is $0.18 \%$.

Time histories of the principal tensile stress at dam heel and principal compressive stress at dam toe are plotted in Figure 12. For the solutions by using the viscous-spring boundary and viscous boundary, the maximum principal tensile stresses at dam heel are $4.67 \mathrm{MPa}$ and $4.74 \mathrm{MPa}$, in which the relative error is $1.56 \%$. The minimum principal compressive stresses at dam toe are $-3.21 \mathrm{MPa}$ and $-3.29 \mathrm{MPa}$, in which the relative error is $2.37 \%$.

It could be seen that the agreement between the results of the viscous-spring boundary and viscous boundary is good. The absolute values of relative errors vary between $0.39 \%$ and $2.37 \%$. The relative errors are less than $3 \%$ and are acceptable from an engineering point of view.

3.3. Seismic Analysis of the Jin'anqiao Dam-Foundation-Reservoir System. The Jin'anqiao gravity dam is selected as the second engineering example in this section. It is located on the middle reaches of the Jinsha River, China. The dam body is a high RCC gravity dam with a maximum height of $160 \mathrm{~m}$ and 


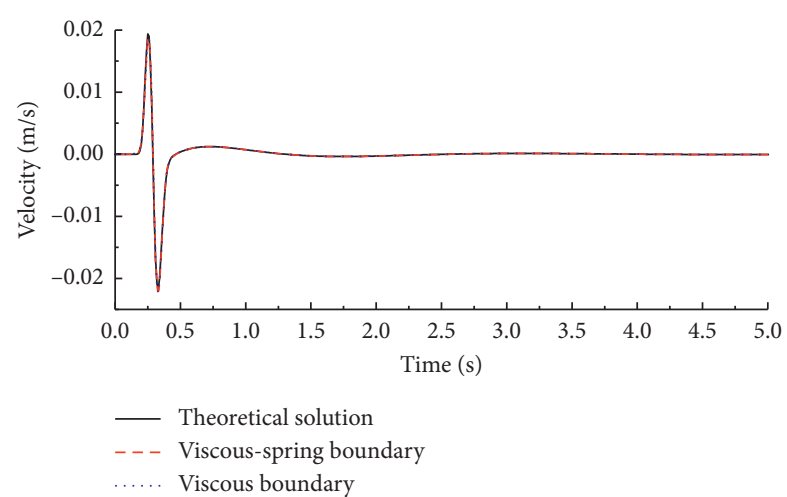

(a)

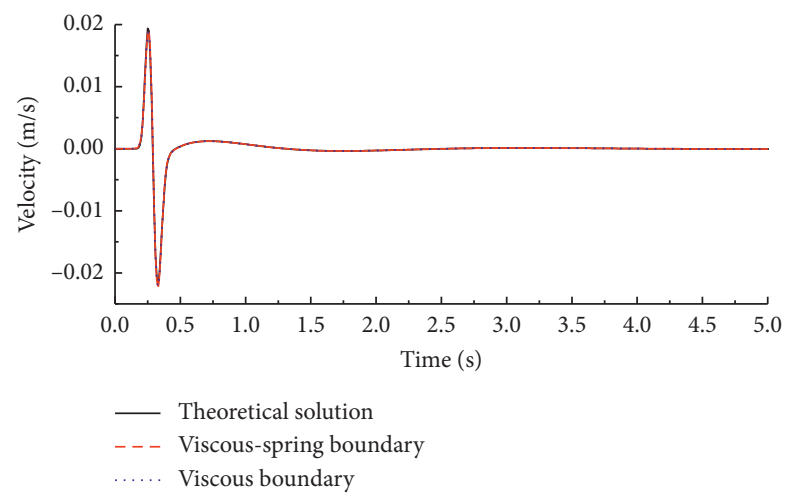

(c)

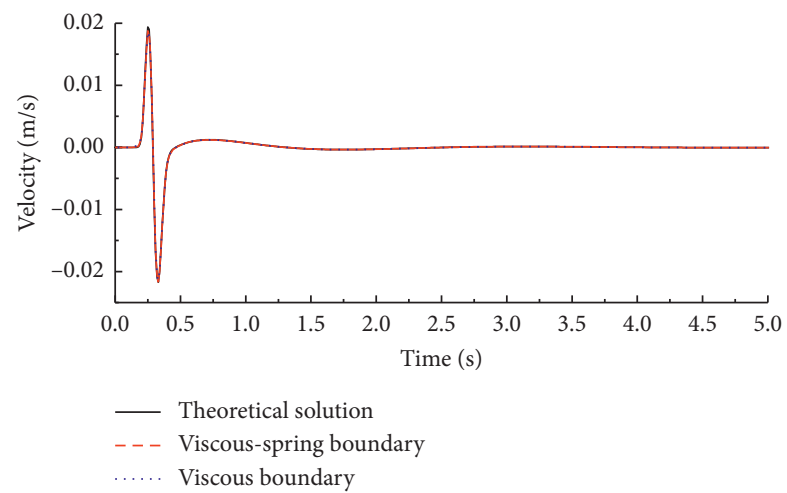

(e)

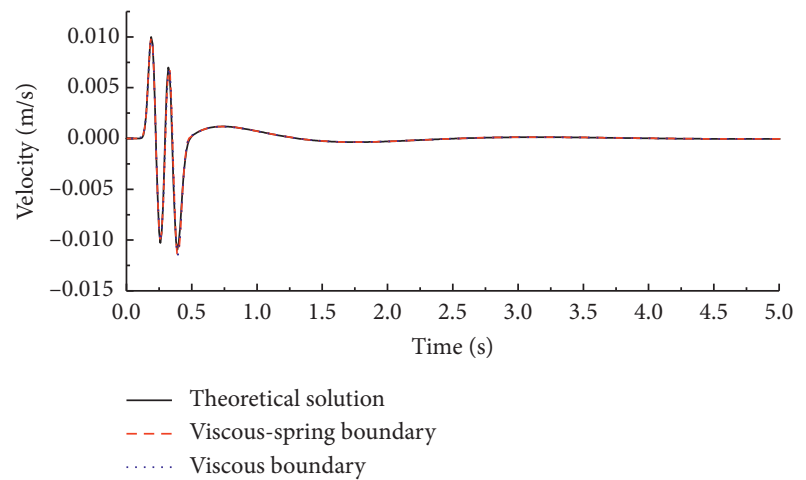

(b)

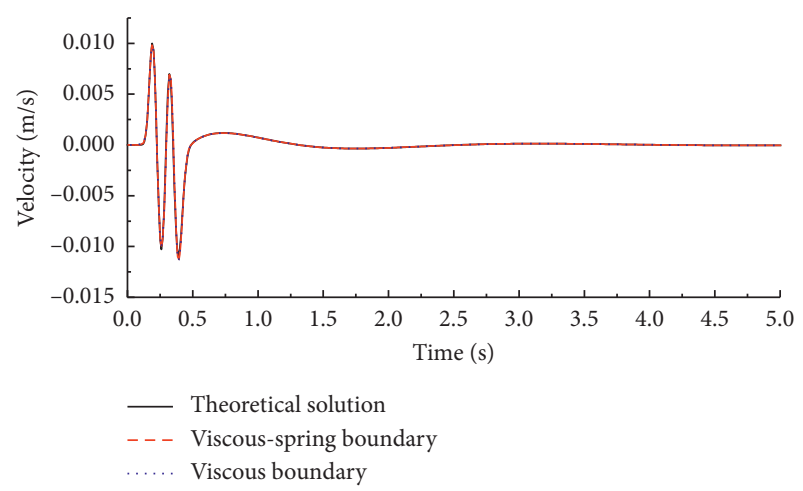

(d)

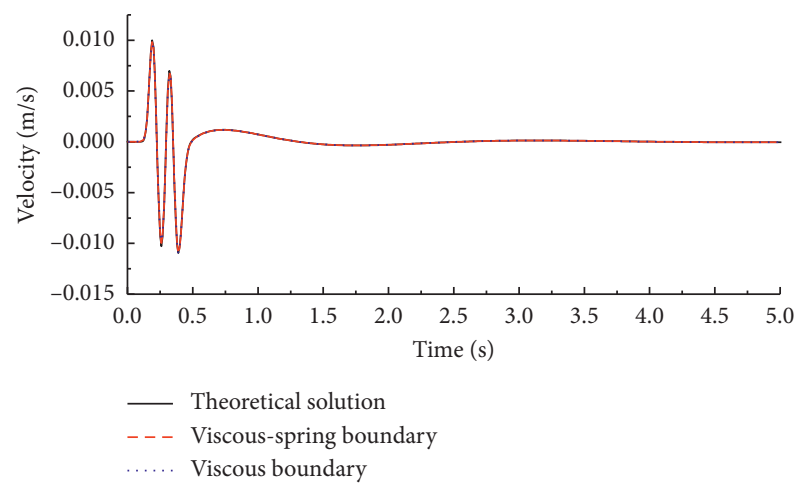

(f)

Figure 4: Comparisons between the numerical and theoretical solutions. (a) Horizontal velocity at point a for SV-wave. (b) Horizontal velocity at point b for SV-wave. (c) Horizontal velocity at point c for SV-wave. (d) Horizontal velocity at point d for SV-wave. (e) Horizontal velocity at point e for SV-wave. (f) Horizontal velocity at point $\mathrm{f}$ for SV-wave.

a crest length of $640 \mathrm{~m}$. The designed horizontal peak ground accelerations (PGA) at the dam site for earthquakes with return periods of 5000 and 10,000 years are $0.399 \mathrm{~g}$ and $0.475 \mathrm{~g}$, respectively. A typical powerhouse monolith is selected as the research subject in this study. The information of the cross-section, material distribution, and model for the simulation is shown in Figure 13.

The mechanical properties of concrete and rock mass are listed in Table 2 . The hydrodynamic pressure wave velocity is $c=1437.8 \mathrm{~m} / \mathrm{s}$, and the density of reservoir water is $\rho_{w}=1000 \mathrm{~kg} / \mathrm{m}^{3}$. Similarly, Rayleigh damping is considered. The constants of proportionality are assumed as $0.7781 / \mathrm{s}$ for $\alpha$ and $0.0077 \mathrm{~s}$ for $\beta$, which corresponds to an approximately $8 \%$ damping ratio for the dam and foundation rock. A $2 \mathrm{D}$ finite element mesh of the Jin'anqiao dam-reservoir-foundation system is shown in Figure 14. The system is discretized with 15591 four-node plane strain elements, leading to 16016 nodes. Likewise, the viscous-spring and viscous boundary and their seismic input models are considered in this example.

In the viscous-spring boundary model, the parameter $r_{b}$ in equation (8) is taken as $455 \mathrm{~m}$. According to the geological data for the Jin'anqiao dam and the standard design response spectrum in GB 51247-2018 [50], two artificial 


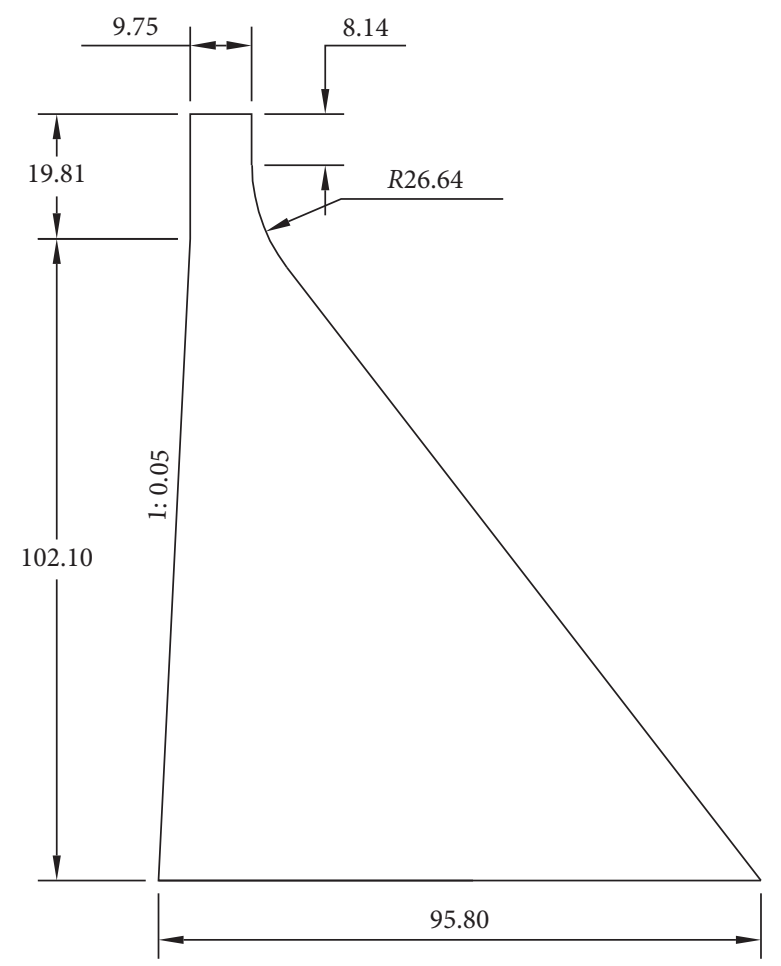

FIgURe 5: Cross-sectional geometry of monolith 16 of the Pine Flat dam (Unit: m).

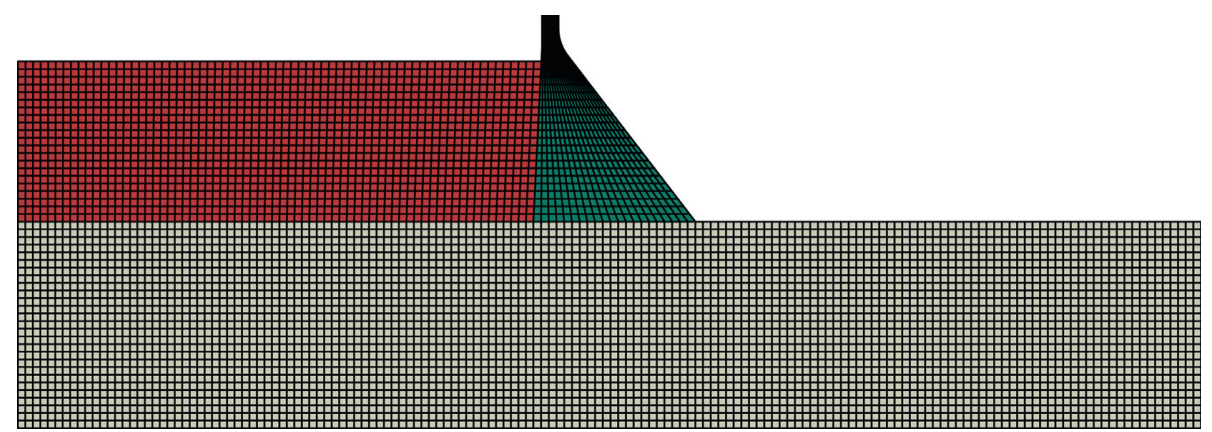

Figure 6: FE mesh of the Pine Flat dam-reservoir-foundation system.
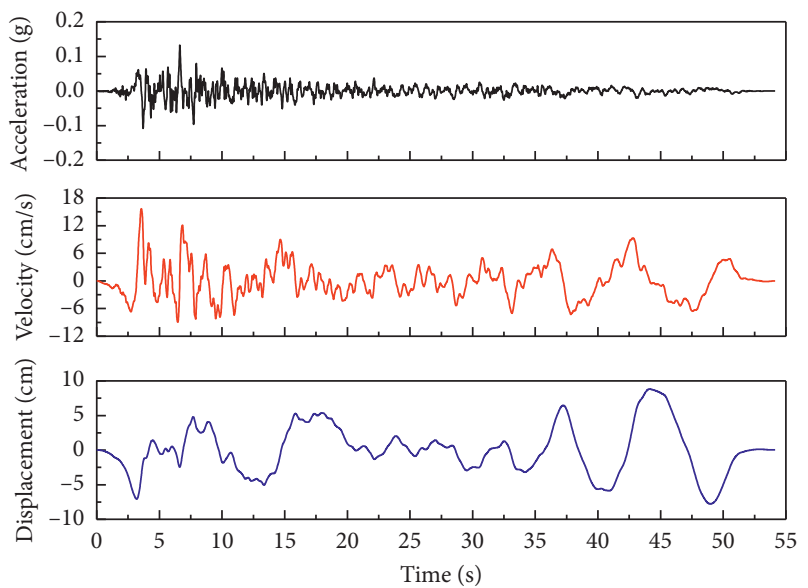

Figure 7: Time histories of the Taft record. ground motions with total time $20 \mathrm{~s}$ are generated. The time histories of acceleration are shown in Figure 15. In the dynamic analysis, the horizontal component is considered as a vertically propagated SV wave, and the vertical component is considered as a vertically propagated $\mathrm{P}$-wave. The fixed time step $\Delta t=0.02 \mathrm{~s}$ is selected in the calculation.

Comparisons of results using different models are listed in Table 3. Time histories of horizontal and vertical displacements at dam crest are plotted in Figure 16. Time histories of horizontal and vertical displacements at dam heel are shown in Figure 17.

For the solutions by using the viscous-spring boundary and viscous boundary, the maximum horizontal displacements at dam crest are $-26.97 \mathrm{~cm}$ and $-26.71 \mathrm{~cm}$, the maximum vertical displacements at dam crest are $-12.18 \mathrm{~cm}$ and $-12.16 \mathrm{~cm}$, the maximum horizontal displacements at 
TABle 1: Result comparisons of the Pine Flat dam using different models.

\begin{tabular}{lccc}
\hline & Viscous-spring boundary & Viscous boundary & Absolute value of relative "error" \\
\hline Maximum horizontal displacement at dam crest & $17.43 \mathrm{~cm}$ & $17.36 \mathrm{~cm}$ & 0.39 \\
Maximum horizontal displacement at dam heel & $17.39 \mathrm{~cm}$ & $17.31 \mathrm{~cm}$ & 0.44 \\
Maximum relative horizontal displacement & $-5.13 \mathrm{~cm}$ & $-5.06 \mathrm{~cm}$ & 1.47 \\
Maximum horizontal acceleration at dam crest & $12.39 \mathrm{~m} / \mathrm{s}^{2}$ & $12.15 \mathrm{~m} / \mathrm{s}^{2}$ & 1.87 \\
Maximum hydrodynamic pressure at dam heel & $-0.2155 \mathrm{MPa}$ & $-0.2159 \mathrm{MPa}$ & 0.18 \\
Maximum principal tensile stress at dam heel & $4.67 \mathrm{MPa}$ & $4.74 \mathrm{MPa}$ & 1.56 \\
Minimum principal compressive stress at dam toe & $-3.21 \mathrm{MPa}$ & $-3.29 \mathrm{MPa}$ & 2.37 \\
\hline
\end{tabular}

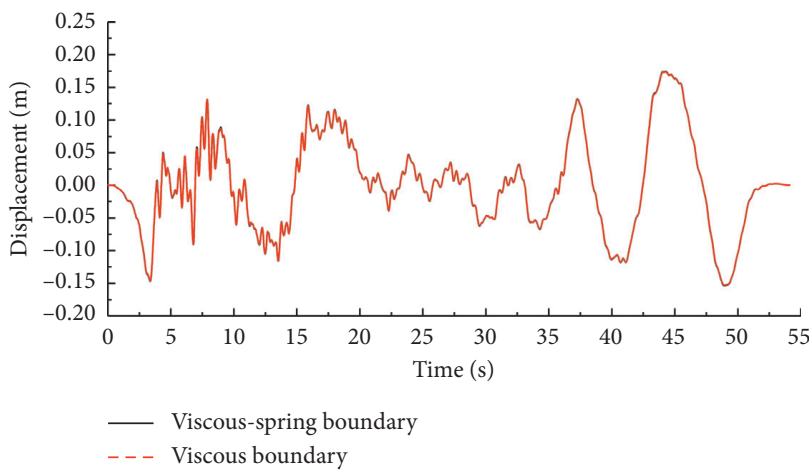

(a)

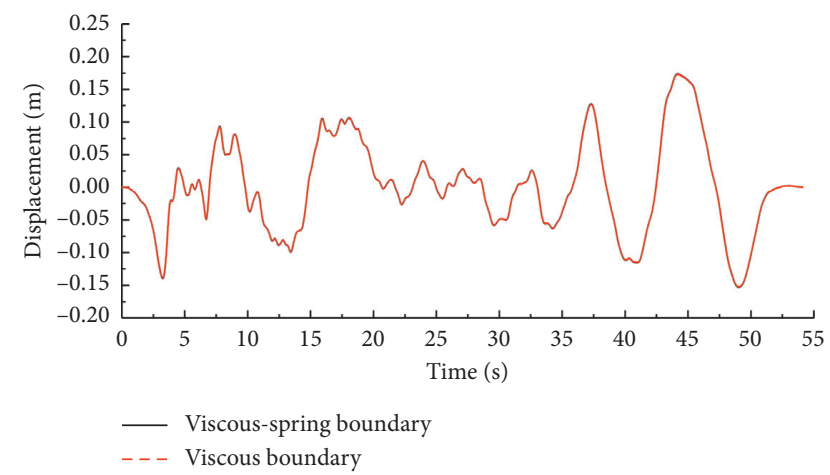

(b)

Figure 8: Time histories of horizontal displacements of the Pine Flat dam. (a) Dam crest. (b) Dam heel.

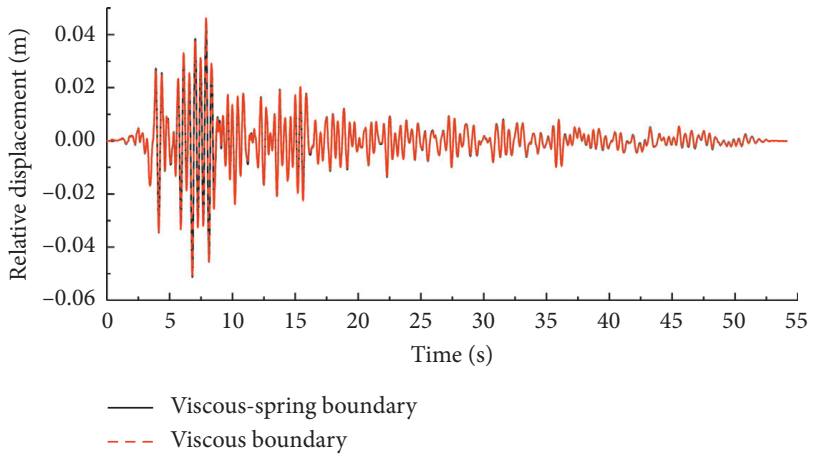

Figure 9: Time histories of relative horizontal displacements of dam crest and dam heel.

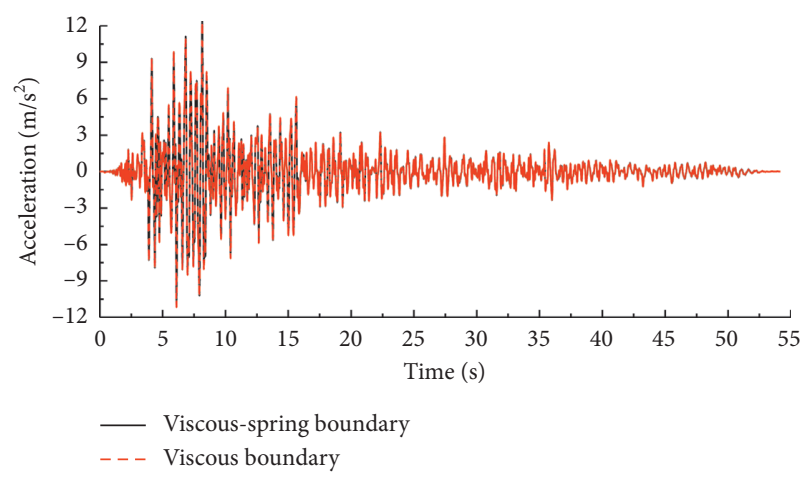

FIgURE 10: Time histories of horizontal accelerations of the Pine Flat dam at dam crest.

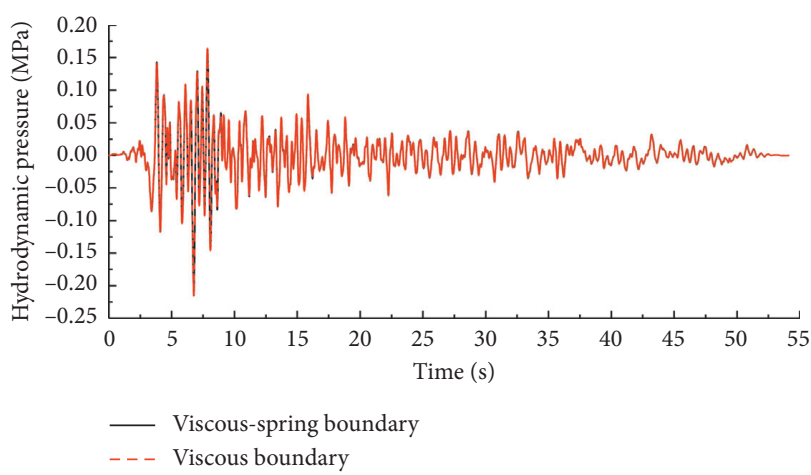

FIgUre 11: Time histories of hydrodynamic pressure of the Pine Flat dam at dam heel.

dam heel are $-15.24 \mathrm{~cm}$ and $-14.93 \mathrm{~cm}$, and the maximum vertical displacements at dam heel are $-10.98 \mathrm{~cm}$ and $-10.88 \mathrm{~cm}$, respectively. The absolute values of the relative error are $0.95 \%, 0.23 \%, 2.04 \%$, and $0.95 \%$, respectively.

Time histories of relative horizontal and vertical displacements of dam crest and dam heel are plotted in Figure 18. The maximum relative horizontal displacements of dam crest and dam heel are $12.76 \mathrm{~cm}$ and $12.96 \mathrm{~cm}$, in which the relative error is $1.58 \%$. The maximum relative horizontal displacements of dam crest and dam heel are $3.42 \mathrm{~cm}$ and $3.43 \mathrm{~cm}$, in which the relative error is $0.33 \%$.

Time histories of horizontal accelerations at dam crest are shown in Figure 19. For the solutions by using the viscous-spring boundary and viscous boundary, the 


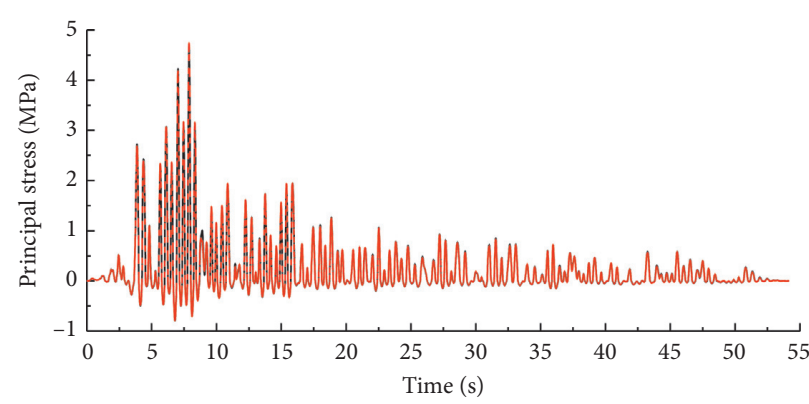

_ Viscous-spring boundary - - - Viscous boundary

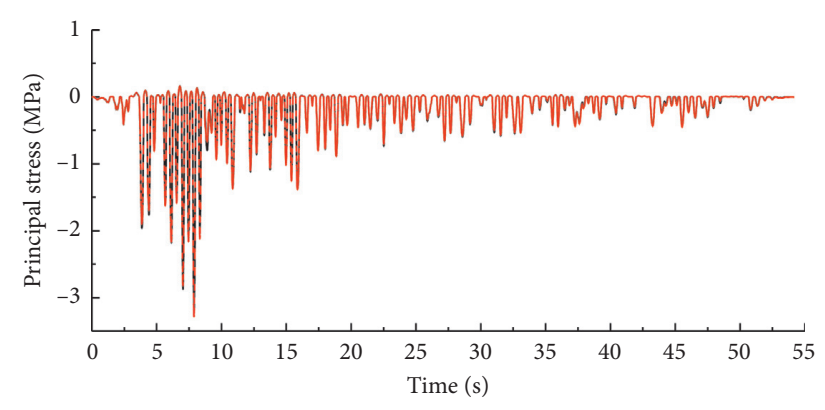

_ Viscous-spring boundary

- - - Viscous boundary

(a)

(b)

Figure 12: Time histories of principal stresses of the Pine Flat dam. (a) Principal tensile stress at dam heel. (b) Principal compressive stress at dam toe.

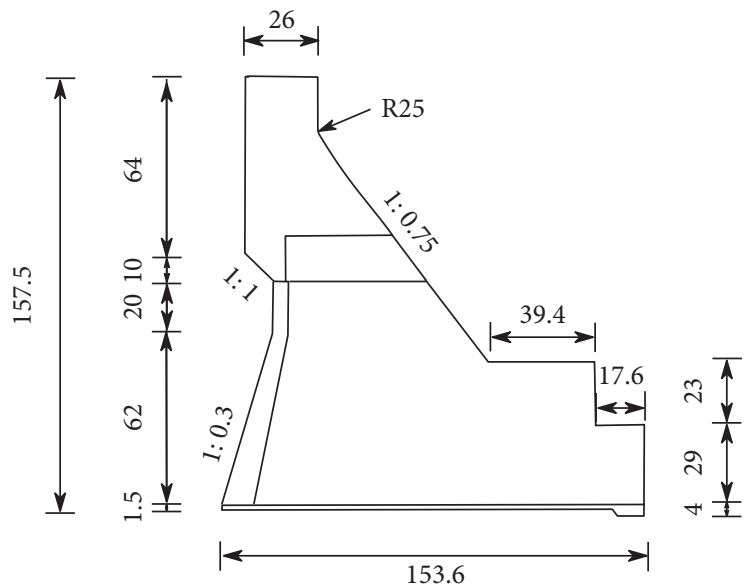

(a)

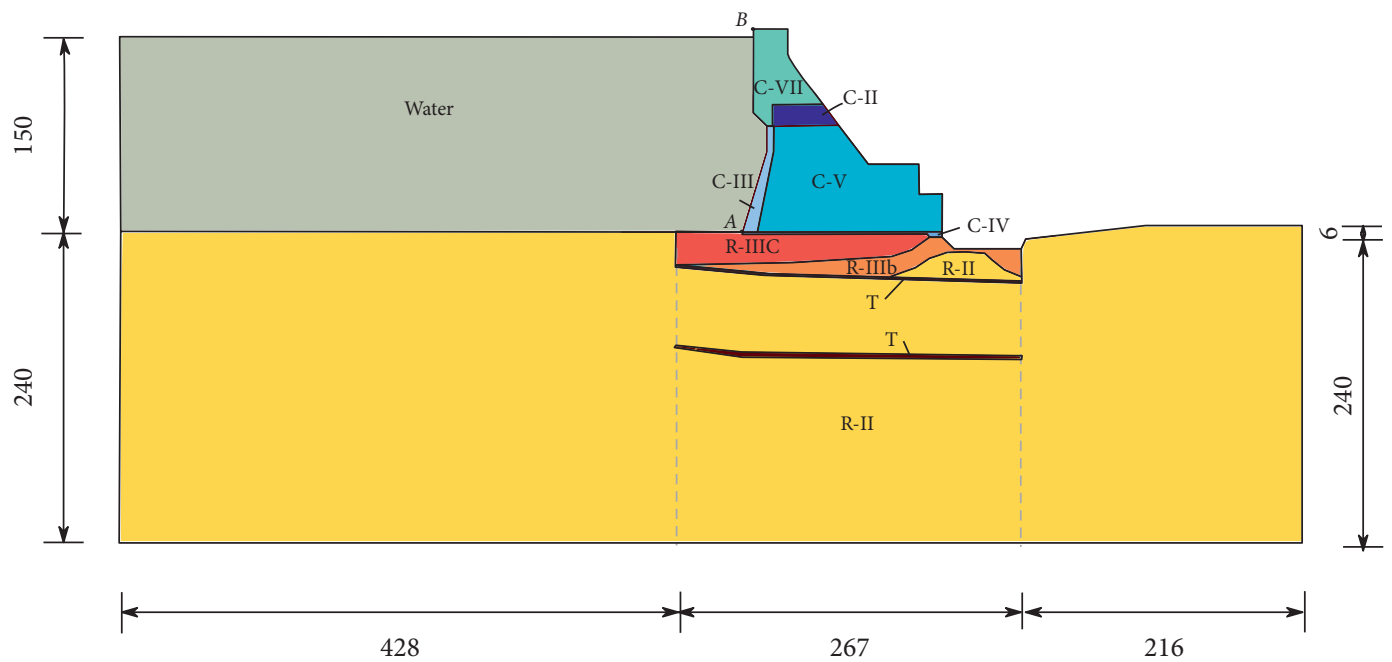

(b)

FIGURE 13: Cross section of the powerhouse monolith of the Jin'anqiao dam (Unit: m). (a) Geometry of the dam. (b) Material distribution and model for the simulation. 
TABle 2: The mechanical properties of concrete and rock mass.

\begin{tabular}{lccc}
\hline Materials & Modulus of elasticity $(\mathrm{GPa})$ & Density $\left(\mathrm{kg} / \mathrm{m}^{3}\right)$ & Poisson's ratio \\
\hline Concrete II & 19.57 & 2600 & 0.167 \\
Concrete III & 20.15 & 2600 & 0.167 \\
Concrete IV & 20.09 & 2600 & 0.167 \\
Concrete V & 18.33 & 2600 & 0.167 \\
Concrete VII & 22.62 & 2600 & 0.167 \\
Rock II & 15 & 2750 & 0.25 \\
Rock IIIb & 10 & 2600 & 0.27 \\
Rock IIIc & 6 & 2500 & 0.28 \\
Weak layer T & 5 & 2500 & 0.28 \\
\hline
\end{tabular}

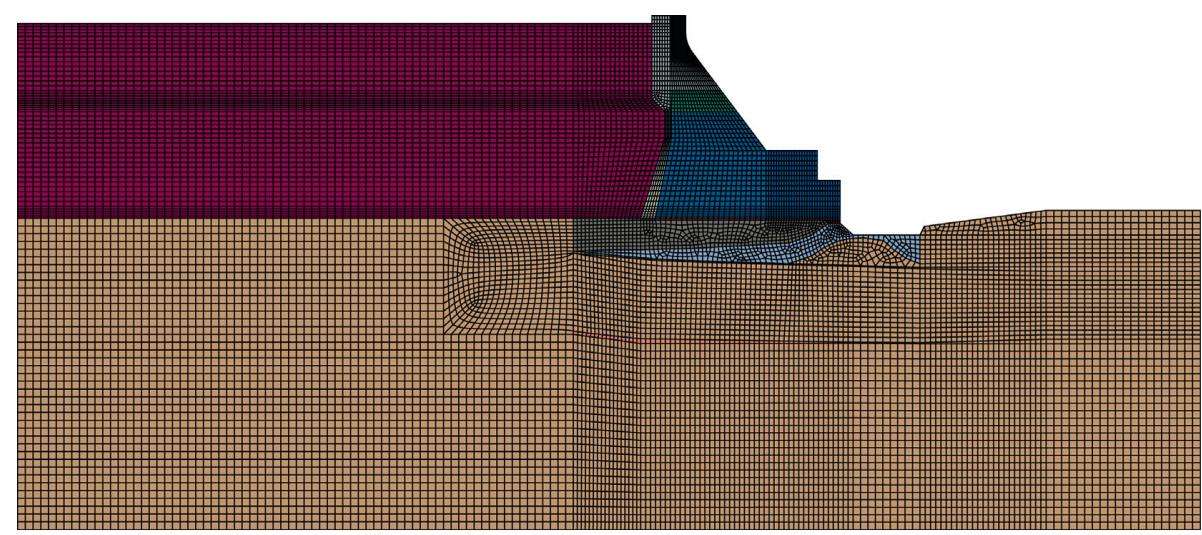

FIGURE 14: FE mesh of the JinJin'anqiao dam-reservoir-foundation system.

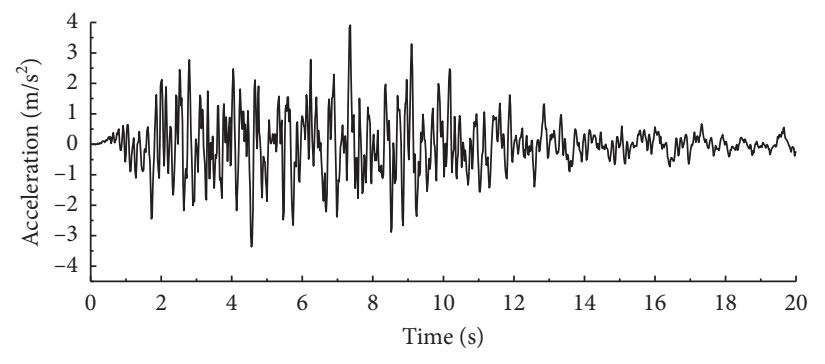

(a)

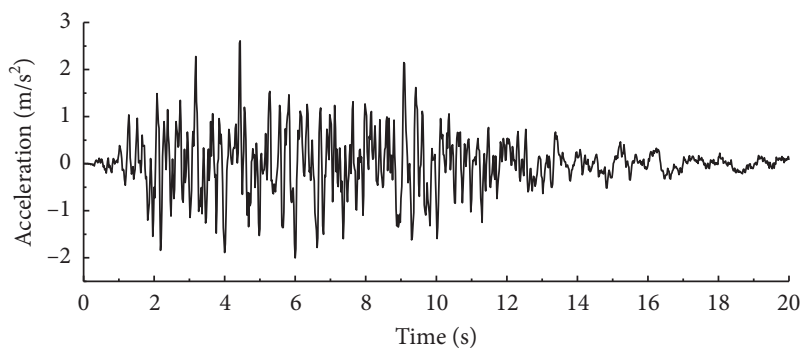

(b)

FIgURE 15: Time histories of input accelerations. (a) Horizontal component (b) Vertical component.

TABle 3: Result comparisons of the Jin'anqiao dam using different models.

\begin{tabular}{|c|c|c|c|}
\hline & Viscous-spring boundary & Viscous boundary & Absolute value of relative "error" (\%) \\
\hline Maximum horizontal displacement at dam crest & $-26.97 \mathrm{~cm}$ & $-26.71 \mathrm{~cm}$ & 0.95 \\
\hline Maximum vertical displacement at dam crest & $-12.18 \mathrm{~cm}$ & $-12.16 \mathrm{~cm}$ & 0.23 \\
\hline Maximum horizontal displacement at dam heel & $-15.24 \mathrm{~cm}$ & $-14.93 \mathrm{~cm}$ & 2.04 \\
\hline Maximum vertical displacement at dam heel & $-10.98 \mathrm{~cm}$ & $-10.88 \mathrm{~cm}$ & 0.95 \\
\hline Maximum relative horizontal displacement & $12.76 \mathrm{~cm}$ & $12.96 \mathrm{~cm}$ & 1.58 \\
\hline Maximum relative vertical displacement & $3.42 \mathrm{~cm}$ & $3.43 \mathrm{~cm}$ & 0.33 \\
\hline Maximum horizontal acceleration at dam crest & $13.24 \mathrm{~m} / \mathrm{s}^{2}$ & $13.32 \mathrm{~m} / \mathrm{s}^{2}$ & 0.58 \\
\hline Maximum hydrodynamic pressure at dam heel & $0.5865 \mathrm{MPa}$ & $0.6071 \mathrm{MPa}$ & 3.50 \\
\hline Maximum principal tensile stress at dam heel & $4.56 \mathrm{MPa}$ & $4.76 \mathrm{MPa}$ & 4.42 \\
\hline Minimum principal compressive stress at dam toe & $-6.89 \mathrm{MPa}$ & $-6.82 \mathrm{MPa}$ & 1.01 \\
\hline
\end{tabular}




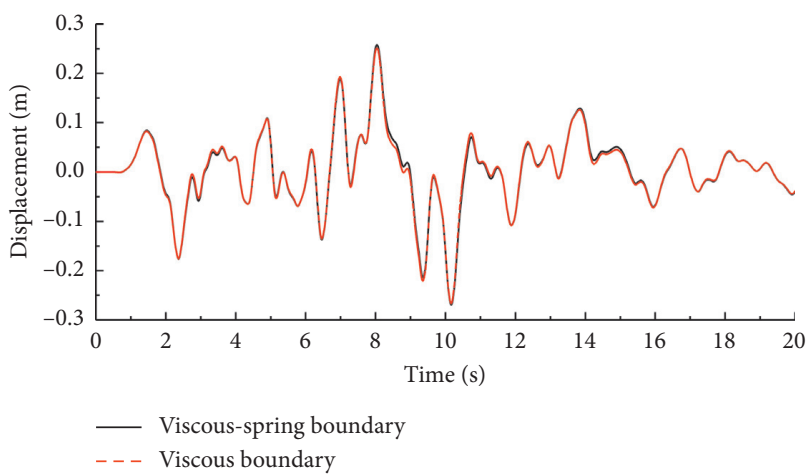

(a)

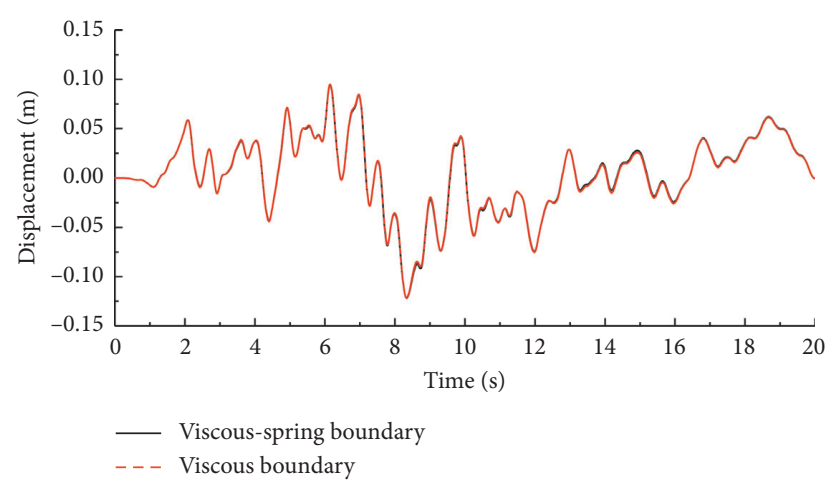

(b)

Figure 16: Time histories of (a) horizontal and (b) vertical displacements at dam crest.

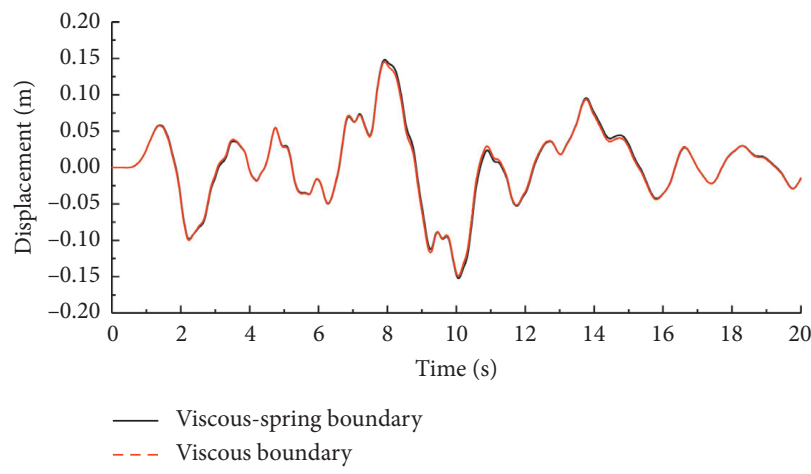

(a)

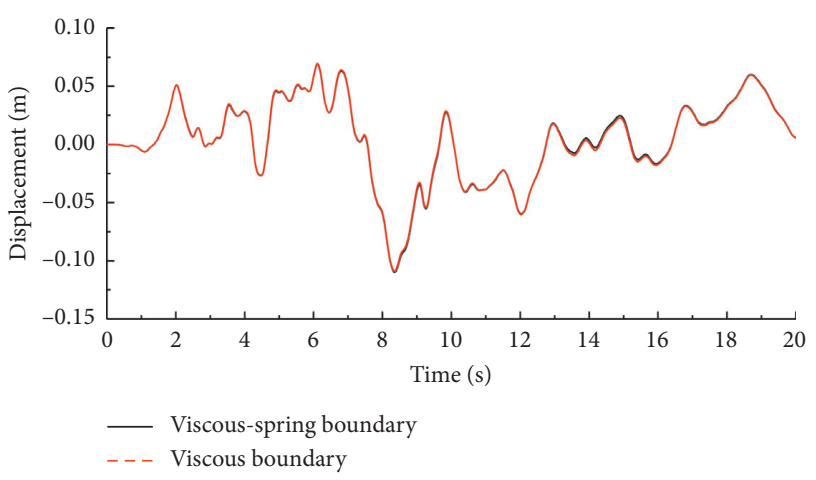

(b)

Figure 17: Time histories of horizontal and vertical displacements at dam heel. (a) Horizontal displacements. (b) Vertical displacements.

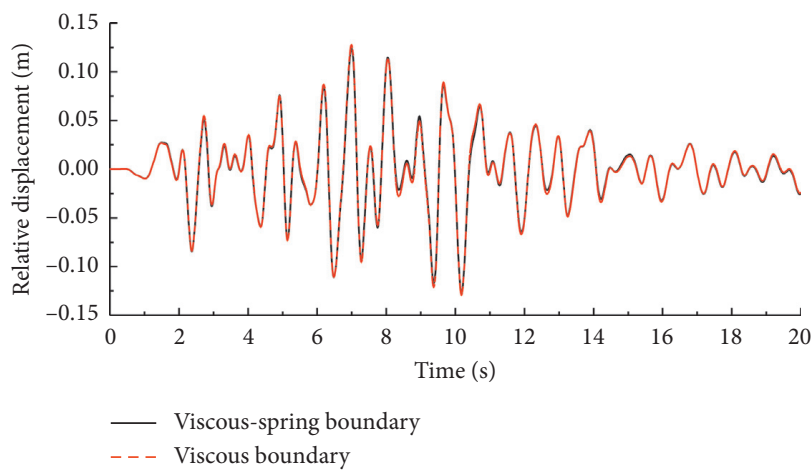

(a)

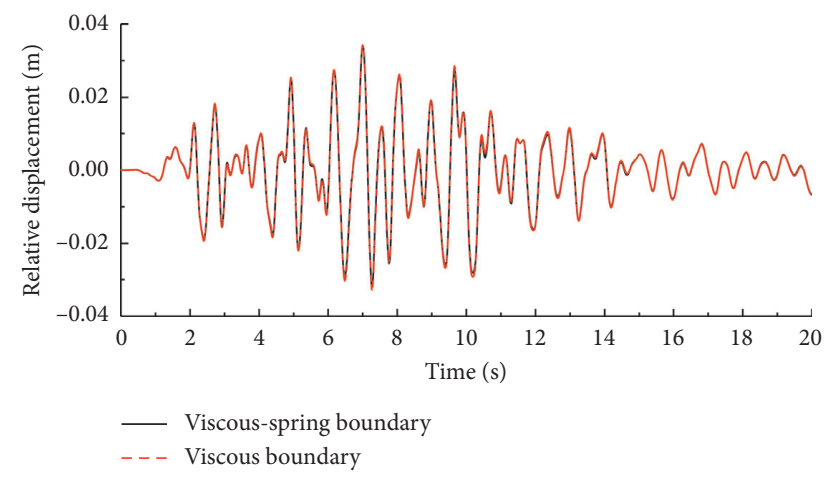

(b)

Figure 18: Time histories of relative displacements of dam crest and dam heel. (a) Horizontal displacements. (b) Vertical displacements.

maximum horizontal accelerations at dam crest are $13.24 \mathrm{~m} /$ $\mathrm{s}^{2}$ and $13.32 \mathrm{~m} / \mathrm{s}^{2}$, in which the relative error is $0.58 \%$. Time histories of the hydrodynamic pressure at dam heel are plotted in Figure 20. For the solutions using the viscousspring boundary and viscous boundary, the maximum hydrodynamic pressures at dam heel are $0.5865 \mathrm{MPa}$ and $0.6071 \mathrm{MPa}$, in which the relative error is $3.50 \%$.
Time histories of the principal tensile stress at dam heel and principal compressive stress at dam toe are shown in Figure 21. For the solutions using the viscousspring boundary and viscous boundary, the maximum principal tensile stresses at dam heel are $4.56 \mathrm{MPa}$ and 4.76 MPa, and the minimum principal compressive stresses at dam toe are $-6.89 \mathrm{MPa}$ and $-6.82 \mathrm{MPa}$, 


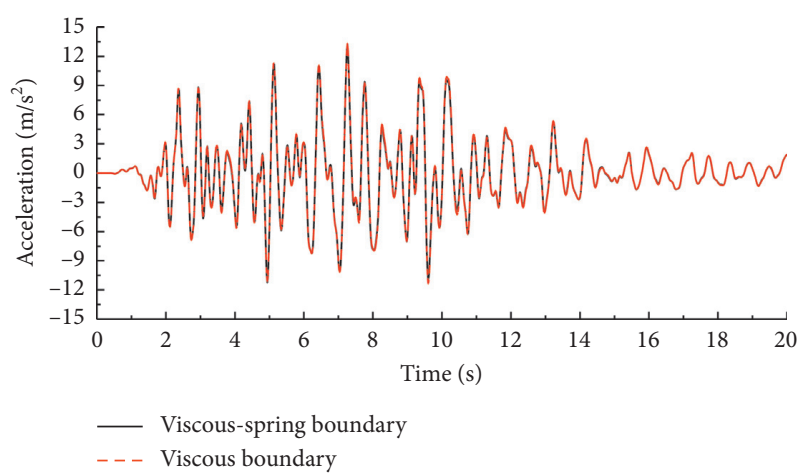

FIgURE 19: Time histories of horizontal accelerations of the Jin'anqiao dam at dam crest.

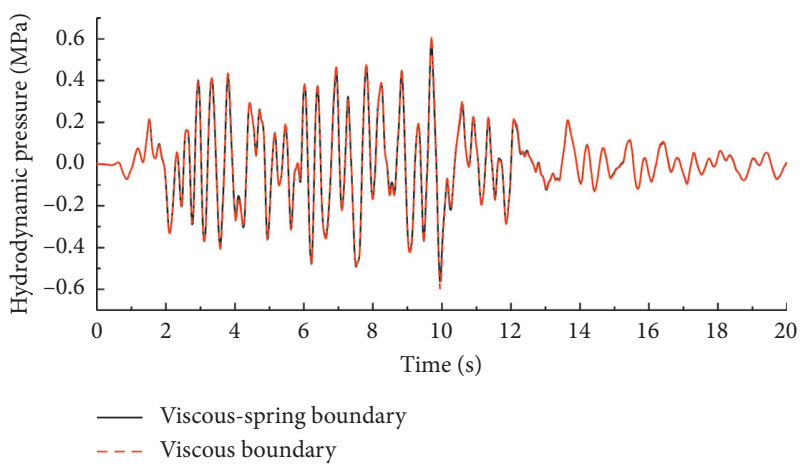

FIGURE 20: Time histories of hydrodynamic pressure of the Jin'anqiao dam at dam heel.

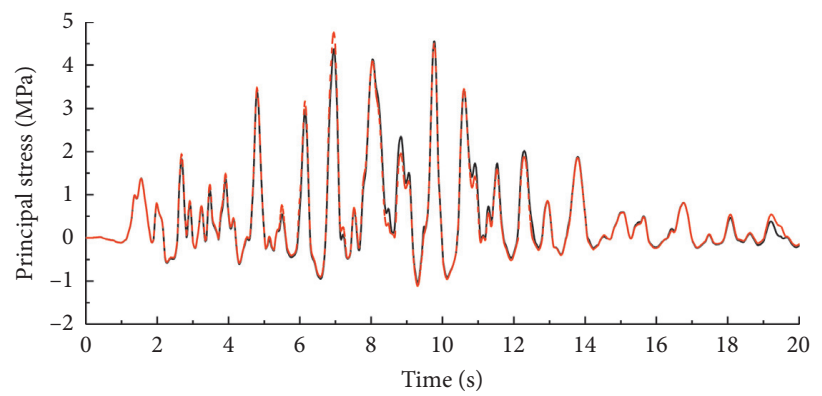

- Viscous-spring boundary

- - - Viscous boundary

(a)

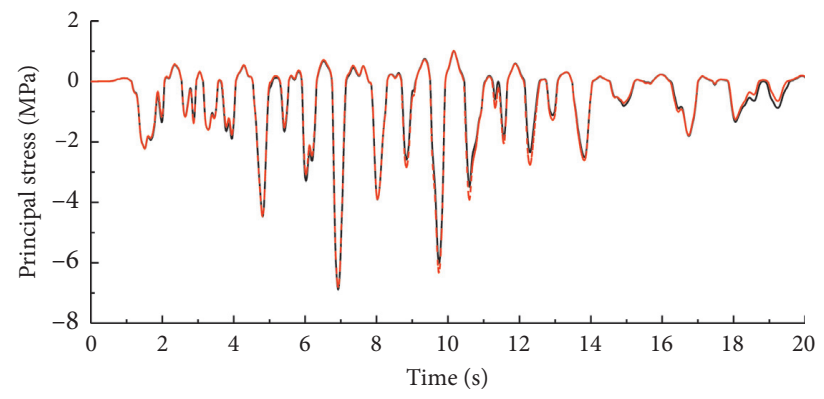

Viscous-spring boundary

- - Viscous boundary

(b)

Figure 21: Time histories of principal stresses of the Jin'anqiao dam. (a) Principal tensile stress at dam heel. (b) Principal compressive stress at dam toe. 
respectively. The absolute values of relative error are $4.42 \%$ and $1.01 \%$, respectively.

It could be seen that the agreement between the results of the viscous-spring boundary and viscous boundary is also good in this case. The absolute values of relative errors vary between $0.23 \%$ and $4.42 \%$. The relative errors are less than $5 \%$ and are acceptable from an engineering point of view.

\section{Conclusion}

In this study, the viscous-spring boundary and the viscous boundary are employed to consider the radiation damping of the unbounded rock foundation. The seismic input models of the viscous-spring boundary and the viscous boundary are derived. The accuracy of the two boundary conditions in the dynamic analysis of the dam foundation is verified through the foundation analysis using an impulsive load. A very good agreement with the theoretical solution is observed for these results using the viscousspring and the viscous boundary conditions in the foundation analysis. The influences of two boundary conditions and their earthquake input models on the seismic analysis of the Pine Flat and Jin'anqiao gravity dam-foundation-reservoir systems are then investigated. The results of displacements, hydrodynamic pressure, and principal stresses show that the agreement between the results of the viscous-spring boundary and viscous boundary is good. For the Pine Flat gravity dam, the absolute values of relative errors vary between $0.39 \%$ and $2.37 \%$. For the Jin'anqiao gravity dam, the absolute values of relative errors vary between $0.23 \%$ and $4.42 \%$. The relative errors of the two engineering examples are both less than 5\%. They are both acceptable from an engineering point of view. Two-dimensional seismic analysis of the gravity dam-foundation-reservoir systems have been carried out in this study. Future works will be extended to three-dimensional linear and nonlinear analysis of the arch dam-foundation-reservoir systems.

\section{Data Availability}

The data used to support the findings of this study are available from the corresponding author upon request.

\section{Conflicts of Interest}

The authors declare that there are no conflicts of interest.

\section{Acknowledgments}

This work was supported by the National Natural Science Foundation of China (Grant no. 52079072), the Natural Science Foundation of Hubei Province (Grant no. 2018CFB652), and the Open Research Fund of State Key Laboratory of Simulation and Regulation of Water Cycle in River Basin, China Institute of Water Resources and Hydropower Research (Grant no. IWHR-SKL-201716).

\section{References}

[1] R. W. Clough, J. M. Raphael, and S. Mojtahedi, "ADAP-A computer program for static and dynamic analysis of arch dams," Report No. EERC 73-14, Earthquake Engineering Research Center, University of California, Berkeley, CA, USA, 1973.

[2] K. Fok, J. F. Hall, and A. K. Chopra, "EACD-3D: a computer program for three-dimensional earthquake analysis of concrete dams," Report No. UCB/EERC-86/09, Earthquake Engineering Research Center, University of California at Berkeley, Berkeley, CA, USA, 1986.

[3] G. L. Fenves, S. Mojtahedi, and R. B. Reimer, "ADAP-88: a computer program for nonlinear earthquake analysis of concrete arch dams," Report No. UCB/EERC-89/12, Earthquake Engineering Research Center, University of California at Berkeley, Berkeley, CA, USA, 1989.

[4] US Army, "Corps of engineers, engineering and design-time-history dynamic analysis of concrete hydraulic structures," Report No. EM1110-2-6051, Department of the Army, Washington, DC, USA, 2003.

[5] A. K. Chopra, "Earthquake analysis of arch dams: factors to be considered," Journal of Structural Engineering, vol. 138, no. 2, pp. 205-214, 2012.

[6] S. Golchin, R. Attarnejad, and S. Vahdani, "Numerical uncoupling of domains in dam-reservoir problem," Shock and Vibration, vol. 2018, Article ID 4369240, 11 pages, 2018.

[7] P. Lin, W. Zheng, B. Huang, and H. Zhang, "Seismic fortification analysis of the Guoduo gravity dam in Tibet, China," Shock and Vibration, vol. 2015, Article ID 396124, 15 pages, 2015.

[8] J. Lysmer and R. L. Kuhlemeyer, "Finite dynamic model for infinite media," Journal of the Engineering Mechanics Division, vol. 95, no. 4, pp. 859-877, 1969.

[9] A. J. Deeks and M. F. Randolph, "Axisymmetric time-domain transmitting boundaries," Journal of Engineering Mechanics, vol. 120, no. 1, pp. 25-42, 1994.

[10] J. Liu, Y. Du, X. Du, Z. Wang, and J. Wu, "3D viscous-spring artificial boundary in time domain," Earthquake Engineering and Engineering Vibration, vol. 5, no. 1, pp. 93-102, 2006.

[11] X. Du and M. Zhao, "A local time-domain transmitting boundary for simulating cylindrical elastic wave propagation in infinite media," Soil Dynamics and Earthquake Engineering, vol. 30, no. 10, pp. 937-946, 2010.

[12] J. Pan and J. Wang, "Effect of abutment movements on nonlinear seismic response of an arch dam," Structure and Infrastructure Engineering, vol. 16, no. 8, pp. 1106-1120, 2020.

[13] Z. P. Liao and H. L. Wong, "A transmitting boundary for the numerical simulation of elastic wave propagation," International Journal of Soil Dynamics and Earthquake Engineering, vol. 3, no. 4, pp. 174-183, 1984.

[14] J. Huang, "An incrementation-adaptive multi-transmitting boundary for seismic fracture analysis of concrete gravity dams," Soil Dynamics and Earthquake Engineering, vol. 110, pp. 145-158, 2018.

[15] J. P. Wolf and C. M. Song, Finite Element Modelling of Unbounded Media, John Wiley \& Sons, Inc., New York, NY, USA, 1996.

[16] C. Song and J. P. Wolf, "The scaled boundary finite-element method-alias consistent infinitesimal finite-element cell method-for elastodynamics," Computer Methods in Applied Mechanics and Engineering, vol. 147, no. 3-4, pp. 329-355, 1997. 
[17] C. M. Song, The Scaled Boundary Finite Element Method: Introduction to Theory and Implementation, John Wiley \& Sons, Inc., New York, NY, USA, 2018.

[18] D. Chen and S. Dai, "Dynamic fracture analysis of the soilstructure interaction system using the scaled boundary finite element method," Engineering Analysis with Boundary Elements, vol. 77, pp. 26-35, 2017.

[19] M. H. Bazyar and C. Song, "Analysis of transient wave scattering and its applications to site response analysis using the scaled boundary finite-element method," Soil Dynamics and Earthquake Engineering, vol. 98, pp. 191-205, 2017.

[20] P. Bettess, Infinite Elements, Penshaw Press, Sunderland, UK, 1992.

[21] C. B. Zhao, Dynamic and Transient Infinite Elements: Theory and Geophysical, Geotechnical and Geoenvironmental Applications, Springer, Berlin, Germany, 2009.

[22] J. Huang and A. Zerva, "Earthquake performance assessment of concrete gravity dams subjected to spatially varying seismic ground motions," Structure and Infrastructure Engineering, vol. 10, no. 8, pp. 1011-1026, 2014.

[23] M. A. Hariri-Ardebili, S. M. Seyed-Kolbadi, and M. R. Kianoush, "FEM-based parametric analysis of a typical gravity dam considering input excitation mechanism," Soil Dynamics and Earthquake Engineering, vol. 84, pp. 22-43, 2016.

[24] U. Basu and A. K. Chopra, "Perfectly matched layers for transient elastodynamics of unbounded domains," International Journal for Numerical Methods in Engineering, vol. 59, no. 8, pp. 1039-1074, 2004.

[25] A. Khazaee and V. Lotfi, "Application of perfectly matched layers in the transient analysis of dam-reservoir systems," Soil Dynamics and Earthquake Engineering, vol. 60, pp. 51-68, 2014.

[26] M. K. Poul and A. Zerva, "Comparative evaluation of foundation modeling for SSI analyses using two different ABC approaches: applications to dams," Engineering Structures, vol. 200, Article ID 109725, 2019.

[27] A. Burman, P. Nayak, P. Agrawal, and D. Maity, "Coupled gravity dam-foundation analysis using a simplified direct method of soil-structure interaction," Soil Dynamics and Earthquake Engineering, vol. 34, no. 1, pp. 62-68, 2011.

[28] M. A. Hariri-Ardebili and H. Mirzabozorg, "A comparative study of seismic stability of coupled arch damfoundation-reservoir systems using infinite elements and viscous boundary models," International Journal of Structural Stability and Dynamics, vol. 13, no. 6, pp. 1-24, 2013.

[29] M. A. Hariri-Ardebili and M. R. Kianoush, "Seismic analysis of a coupled dam-reservoir-foundation system considering pressure effects at opened joints," Structure and Infrastructure Engineering, vol. 11, no. 7, pp. 833-850, 2015.

[30] K. K. Mandal and D. Maity, "Transient response of concrete gravity dam considering dam-reservoir-foundation interaction," Journal of Earthquake Engineering, vol. 22, no. 2, pp. 211-233, 2018.

[31] A. Løkke and A. K. Chopra, "Direct finite element method for nonlinear analysis of semi-unbounded dam-water-foundation rock systems," Earthquake Engineering and Structural Dynamics, vol. 46, no. 8, pp. 1267-1285, 2017.

[32] A. Løkke and A. K. Chopra, "Direct finite element method for nonlinear earthquake analysis of 3-dimensional semi-unbounded dam-water-foundation rock systems," Earthquake Engineering and Structural Dynamics, vol. 47, no. 8, pp. 1309-1328, 2018.
[33] A. Løkke and A. K. Chopra, "Direct finite element method for nonlinear earthquake analysis of concrete dams: simplification, modeling, and practical application," Earthquake Engineering and Structural Dynamics, vol. 48, no. 8, pp. 818-842, 2019.

[34] H. Mohammadnezhad, M. Ghaemian, and A. Noorzad, "Seismic analysis of dam-foundation-reservoir system including the effects of foundation mass and radiation damping," Earthquake Engineering and Engineering Vibration, vol. 18, no. 1, pp. 203-218, 2019.

[35] P. Sotoudeh, M. Ghaemian, and H. Mohammadnezhad, "Seismic analysis of reservoir-gravity dam-massed layered foundation system due to vertically propagating earthquake," Soil Dynamics and Earthquake Engineering, vol. 116, pp. 174-184, 2019.

[36] M. Karalar and M. Çavuşli, "Assessing 3D seismic damage performance of a CFR dam considering various reservoir heights," Earthquakes and Structures, vol. 16, no. 2, pp. 221-234, 2019.

[37] M. Karalar and M Çavuşli, "Examination of 3D long-term viscoplastic behaviour of a CFR dam using special material models," Geomechanics and Engineering, vol. 17, no. 2, pp. 119-131, 2019.

[38] M. Karalar and M Çavuşli, "Seismic effects of epicenter distance of earthquake on 3D damage performance of CG dam," Earthquakes and Structures, vol. 18, no. 2, pp. 201-213, 2020.

[39] C. H. Zhang, J. W. Pan, and J. T. Wang, "Influence of seismic input mechanisms and radiation damping on arch dam response," Soil Dynamics and Earthquake Engineering, vol. 29, no. 9, pp. 1282-1293, 2009.

[40] J. Pan, C. Zhang, J. Wang, and Y. Xu, "Seismic damagecracking analysis of arch dams using different earthquake input mechanisms," Science in China Series E: Technological Sciences, vol. 52, no. 2, pp. 518-529, 2009.

[41] D.-H. Chen, C.-B. Du, J.-W. Yuan, and Y.-W. Hong, "An investigation into the influence of damping on the earthquake response analysis of a high arch dam," Journal of Earthquake Engineering, vol. 16, no. 3, pp. 329-349, 2012.

[42] J.-T. Wang, D.-D. Lv, F. Jin, and C.-H. Zhang, "Earthquake damage analysis of arch dams considering dam-water-foundation interaction," Soil Dynamics and Earthquake Engineering, vol. 49, pp. 64-74, 2013.

[43] A. Mandal and D. Maity, "Finite element analysis of damfoundation coupled system considering cone-type local nonreflecting boundary condition," Journal of Earthquake Engineering, vol. 20, no. 3, pp. 428-446, 2016.

[44] D.-H. Chen, Z.-H. Yang, M. Wang, and J.-H. Xie, "Seismic performance and failure modes of the Jin'anqiao concrete gravity dam based on incremental dynamic analysis," Engineering Failure Analysis, vol. 100, pp. 227-244, 2019.

[45] S. S. Guo, H. Liang, Y. R. Deng et al., "The effect of steel reinforcement on seismic damage to concrete gravity dams based on distributed-steel model," Journal of Earthquake and Tsunami, vol. 14, no. 2, Article ID 2050010, 2020.

[46] ABAQUS Inc, Abaqus Theory Manual, Version 6.14, ABAQUS, Inc., Providence, RI, USA, 2014.

[47] J. W. Salamon, C. Wood, M. A. Hariri-Ardebili, R. Malm, and G. Faggiani, "Seismic analysis of pine flat concrete dam: formulation and synthesis of results," in G. Bolzon, D. Sterpi, G. Mazzá, A. Frigerio (eds), Numerical Analysis of Dams. ICOLD-BW 2019, Lecture Notes in Civil Engineering, vol. 91, Springer, Cham, Switzerland, 2021. 
[48] G. Wang, Y. Wang, W. Lu, P. Yan, and M. Chen, "Earthquake direction effects on seismic performance of concrete gravity dams to mainshock-aftershock sequences," Journal of Earthquake Engineering, vol. 24, no. 7, pp. 1134-1155, 2020.

[49] U.S. Department of the Interior, Evaluation of Numerical Models and Input Parameters in the Analysis of Concrete Dams, a Summary Report of the United States Society on Dams (USSD) Workshop, Dam Safety Report DSO-19-13, Bureau of Reclamation, Denver, CO, USA, 2018.

[50] Ministry of Housing and Urban-Rural Development of the People's Republic of China, Standard for Seismic Design of Hydraulic Structures, GB 51247-2018, Ministry of Housing and Urban-Rural Development of the People's Republic of China, Beijing, China, 2018, in Chinese. 